\title{
Comment on: Secondary impacts of constipation in acute lymphoblastic leukemia in U.S. children's hospitals
}

\author{
Rameez $\mathrm{Naqvi}^{1}$, Saif Chatoo ${ }^{2}$, and Zayn Ahmad ${ }^{3}$ \\ ${ }^{1} \mathrm{UCL}$ \\ ${ }^{2}$ Cardiff University Department of Medicine \\ ${ }^{3}$ Queen Mary University of London Barts and The London School of Medicine and \\ Dentistry
}

September 25, 2021

Comment on: Secondary impacts of constipation in acute lymphoblastic leukemia in U.S. children's hospitals Rameez Naqvi ${ }^{1}$, Saif Abbas Chatoo ${ }^{2}$, Zayn Ahmad ${ }^{3}$

${ }^{1}$ UCL Medical School

${ }^{2}$ Cardiff School of Medicine

${ }^{3}$ Barts and The London School of Medicine and Dentistry

* Correspondence to:

Rameez Naqvi, UCL Medical School, 74 Huntley St, London WC1E 6DE, Tel.: 07851081725, Email: zchanaq@ucl.ac.uk

Text word count 493;

Abstract word count: N/A;

Brief running title: Letter to the Editor

Key words: Chemotherapy, ALL, Pediatric oncology

Tables: 0

Figures: 0

We read, with great interest, the article by Belsky et al. on the effects of constipation in pediatric oncology patients, particularly looking at children who had undergone induction therapy for Acute Lymphoblastic Leukemia $(\mathrm{ALL})^{1}$. As medical students who have recently had pediatric and oncology placements, we would like to share our thoughts on what we found to be a fascinating topic.

The process of diagnosing and treating a child with cancer is an extremely distressing period for the patient and parent/carer of the patient. The majority of parents of pediatric oncology patients are said to be either mildly or severely distressed ${ }^{2}$. There is also the challenge that lies with the side effects of chemotherapy along with the struggle in communicating with some young children. Due to side effects, patients can present distressed and require hospital admission, under the guise that it is due to their original condition rather than the treatment. We applaud Belsky et al. for including patients who were readmitted in order to seek psychological support for the side effects of their treatment, as this is a factor often overlooked when looking at readmission data. 
On our placements, the diagnosis of constipation secondary to chemotherapy was difficult to navigate. We found that the side effects of the medication, such as constipation or fatigue, can cause some patient families to feel an incongruency with their agenda and the healthcare providers, as some find it difficult to perceive that the treatment can also cause the child pain. This can cause strain on an already difficult relationship to manage ${ }^{3}$. Although it was beyond the stated scope of this study, this would be an interesting secondary impact of chemotherapy side effects that can be explored in the same demographic of patients.

As mentioned by Belsky et al., it can be difficult to attribute the constipation solely to the medication being used. There are a variety of confounding factors that can arise during induction therapy that can also cause constipation - dietary changes due to hospital admission, lack of water intake due to fatigue and lack of energy to exercise, to name a few. To further expand the study, looking into these factors and their magnitude of effect would provide a clearer understanding of the secondary effects of constipation.

The study defined constipation by the presence of a diagnosis code or a patient who is receiving two constipation medications. The author recognizes that patients can receive these medications prophylactically, so ideally there should be a method of investigating the indication in these patients. It must also be said that diagnosis coding means that there is an element of human error which can cause inaccuracies in the data collected. This can be seen in some international studies ${ }^{4}$.

Future retrospective studies should consider investigating the confounding factors and authenticating diagnoses in order to provide a more robust causality. Research into the true effects of chemotherapy in Pediatrics is crucial and we hope to see more research within this field.

\section{References:}

Belsky, J., Batra, S., Stanek, J. and O'Brien, S., 2021. Secondary impacts of constipation in acute lymphoblastic leukemia in U.S. children's hospitals. Pediatric Blood 83 Cancer ,.

Boyden, J., Hill, D., Nye, R., Bona, K., Johnston, E., Hinds, P., Friebert, S., Kang, T., Hays, R., Hall, M., Wolfe, J. and Feudtner, C., 2021. Pediatric palliative care parents' distress, financial difficulty, and child symptoms. Journal of Pain and Symptom Management ,.

Zarkowski, P. and Aksu, M., 2021. Legal and Ethical Issues in Treating Adolescent Patients. Dental Clinics of North America , 65(4), pp.815-826.

Farhan, J., Al-Jummaa, S., Al-Rajhi, A., Al-Rayes, H. and Al-Nasser, A., 2005. Documentation and coding of medical records in a tertiary care center: a pilot study. Annals of Saudi Medicine, 25(1), pp.46-49. 